\title{
Switching Oxygen Reduction Pathway by Exfoliating Graphitic Carbon Nitride for Enhanced Photocatalytic Phenol Degradation
}

\author{
Hui Zhang, Liang-Hong Guo,* Lixia Zhao, Bin Wan, and Yu Yang
}

State Key Laboratory of Environmental Chemistry and Eco-toxicology, Research Centre for Eco-environmental Sciences, Chinese Academy of Sciences, 18 Shuangqing Road, P.O. Box 2871, Beijing 100085, China

\section{Supporting Information}

ABSTRACT: The selectivity of molecular oxygen activation on the exfoliated graphitic carbon nitride $\left(\mathrm{g}-\mathrm{C}_{3} \mathrm{~N}_{4}\right)$ and its influence on the photocatalytic phenol degradation process were demonstrated. Compared with bulk $\mathrm{g}-\mathrm{C}_{3} \mathrm{~N}_{4}$, the exfoliated nanosheet yielded a 3-fold enhancement in photocatalytic phenol degradation. ROS trapping experiments demonstrated that although the direct hole oxidation was mainly responsible for phenol photodegradation on both $\mathrm{g}-\mathrm{C}_{3} \mathrm{~N}_{4}$ catalysts, molecular oxygen activation processes on their surface greatly influenced the whole phenol degradation efficiency. Reactive oxygen species and Raman spectroscopy measurements revealed that oxygen was preferentially reduced to $\cdot \mathrm{O}_{2}^{-}$by one-electron transfer on bulk g- $\mathrm{C}_{3} \mathrm{~N}_{4}$, while on $\mathrm{g}-\mathrm{C}_{3} \mathrm{~N}_{4}$ nanosheet the production of $\mathrm{H}_{2} \mathrm{O}_{2}$ via a

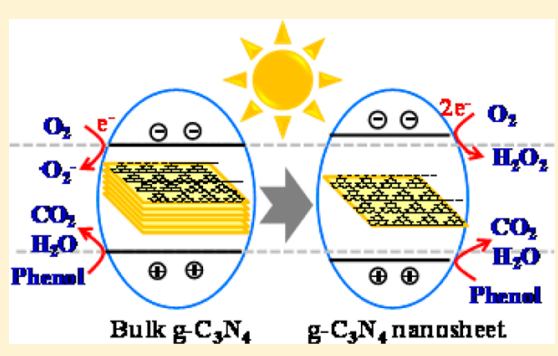
two-electron transfer process was favored due to the rapid formation of surface-stabilized 1,4-endoperoxide. The latter process not only promotes the separation of photogenerated electron-hole pairs but also greatly facilitates reactive oxygen species formation and subsequently enhances phenol degradation.

$\mathrm{W}$ ith the escalating concerns on environmental pollution, sunlight-driven photocatalytic reactions over semiconducting materials for contaminant degradation have attracted considerable attention. ${ }^{1-3}$ Upon light excitation, photogenerated electrons and holes can either recombine or migrate to the semiconductor surface, where they react with the adsorbed molecular oxygen and hydroxyls to generate reactive oxygen species (ROS, typically including $\cdot \mathrm{OH}, \cdot \mathrm{O}_{2}{ }^{-}$, and $\mathrm{H}_{2} \mathrm{O}_{2}$ ) and eventually mineralize contaminants. ${ }^{4-6}$ In particular, as a main electron scavenger in an ambient atmosphere, molecular oxygen reduction by photogenerated electrons on the semiconductor conduction band, which generally proceeds via oneor two-electron transfer, plays a key role or even is the ratedetermining step in the overall reaction because this process not only suppresses electron-hole recombination but also yields ROS.

The pathway of molecular oxygen reduction on the photocatalyst surface is critically dependent on the electronic structure and surface atomic structure of the photocatalyst due to their dominating effect on the redox potentials of photogenerated charges and the adsorption site of reactant molecules, respectively. Previous studies reported that the loading of $\mathrm{Au}$ nanoparticles or $\mathrm{Cu}$ (II) clusters on $\mathrm{TiO}_{2}$ surface facilitated multielectron reduction of $\mathrm{O}_{2}$ to $\mathrm{H}_{2} \mathrm{O}_{2}$ due to the change of surface electronic structure, which efficiently promoted the degradation of aromatics. ${ }^{7,8}$ Recently, Zhao's group reported that the different surface structure between anatase $\mathrm{TiO}_{2}\{001\}$ and $\{101\}$ facets dramatically influenced the pathways of $\mathrm{O}_{2}$ reduction in the photocatalytic reactions. ${ }^{9} \mathrm{~A}$ facet-dependent $\mathrm{O}_{2}$ reduction pathway (one- or two-electron reduction) was also observed on the $\{001\}$ and $\{010\}$ surface of $\mathrm{BiOCl}$ due to the difference in surface atom exposure. ${ }^{10}$ These results clearly suggest that the structural properties can greatly determine the molecular oxygen reduction process. Nevertheless, knowledge on the surface-dependent $\mathrm{O}_{2}$ reduction over photoexcited semiconductor surface is still limited. An in-depth understanding of the above issues is essential to modulating reaction mechanisms and intermediate products and devising practical photocatalytic degradation applications.

Recently, layer-structured semiconductors (e.g., metal-free graphitic carbon nitride, $\mathrm{g}-\mathrm{C}_{3} \mathrm{~N}_{4}$ ) have emerged as attractive visible-light photocatalysts for hydrogen evolution, organic pollutant degradation, and organic synthesis. ${ }^{11-13}$ Layerstructured $\mathrm{g}-\mathrm{C}_{3} \mathrm{~N}_{4}$ makes it easy to tailor the energy band structure by controlling the layer number. Experimental results demonstrated that ultrathin $\mathrm{g}-\mathrm{C}_{3} \mathrm{~N}_{4}$ nanosheets promoted the photocatalytic ability with respect to bulk counterparts owing to their larger surface area and enhanced separation of electron-hole pairs. ${ }^{14,15}$ Despite numerous studies on g- $\mathrm{C}_{3} \mathrm{~N}_{4}$ photocatalysis, the first step of molecular oxygen reduction on this promising photocatalyst has still not been clarified. Inspired by the previous elaborate work, herein we demonstrated the structure-dependent molecular oxygen reduction on bulk and exfoliated $\mathrm{g}-\mathrm{C}_{3} \mathrm{~N}_{4}$ during photocatalysis. The molecular oxygen reduction processes and possible mechanisms for the observed selectivity for the reduction pathway were investigated. Our work highlights the important role of structure-dependent molecular oxygen reduction during photocatalytic reactions.

Received: January 22, 2015

Accepted: February 27, 2015

Published: February 27, 2015 

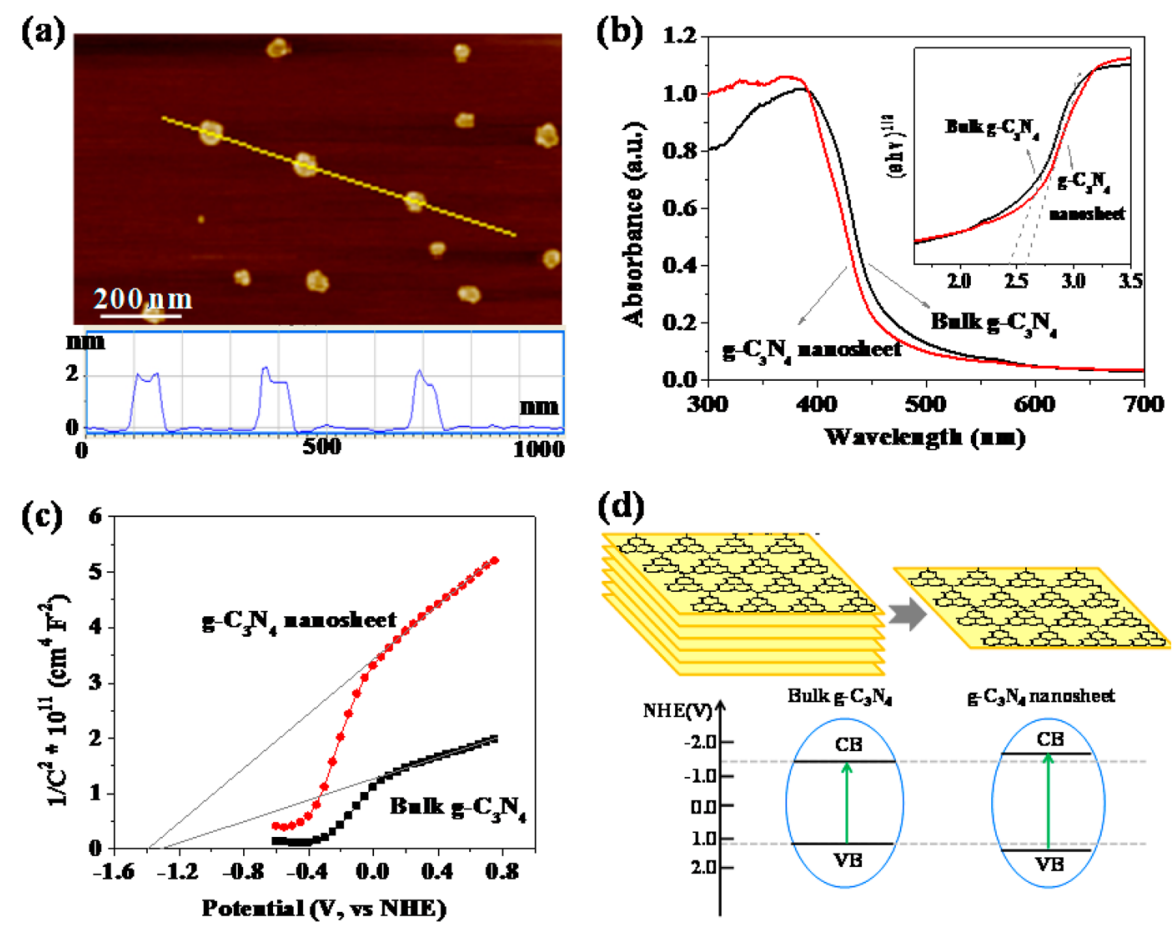

(d)

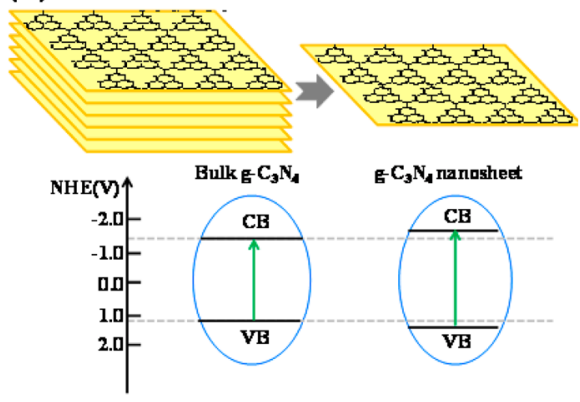

Figure 1. (a) AFM image of g- $\mathrm{C}_{3} \mathrm{~N}_{4}$ nanosheets, (b) UV-vis absorption spectra, (c) Mott-Schottky plots, and (d) schematic illustration of the energy band structures of bulk g- $\mathrm{C}_{3} \mathrm{~N}_{4}$ and $\mathrm{g}-\mathrm{C}_{3} \mathrm{~N}_{4}$ nanosheets.
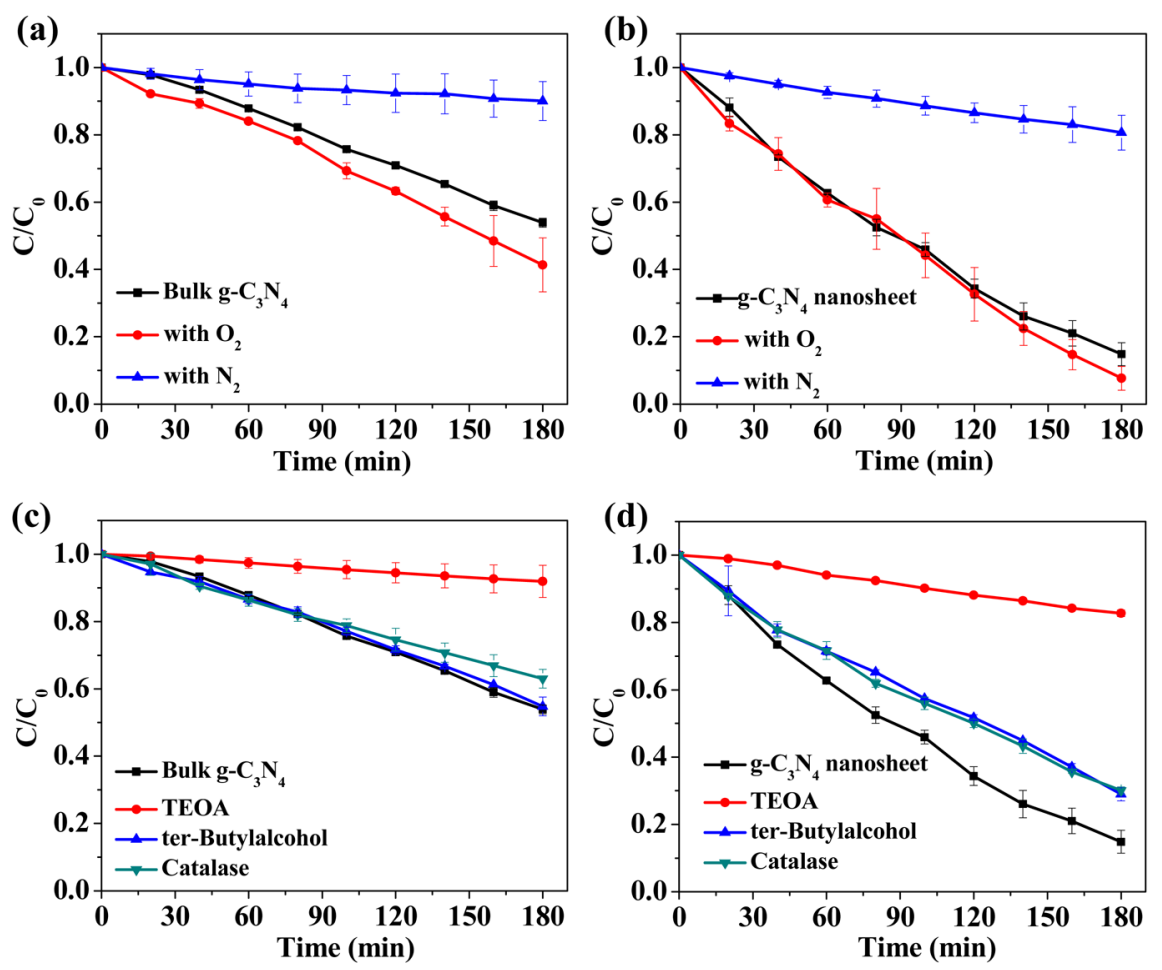

Figure 2. Phenol degradation curves under visible light over (a) bulk $g-\mathrm{C}_{3} \mathrm{~N}_{4}$ and (b) $g-\mathrm{C}_{3} \mathrm{~N}_{4}$ nanosheets in aerated and $\mathrm{N}_{2}$ and $\mathrm{O}_{2}$ bubbling suspensions. Phenol degradation curves in (c) bulk g- $\mathrm{C}_{3} \mathrm{~N}_{4}$ and (d) g- $\mathrm{C}_{3} \mathrm{~N}_{4}$ nanosheet suspensions with the addition of different scavengers (TEOA for hole, tert-butyl alcohol for $\cdot \mathrm{OH}$, catalase for $\mathrm{H}_{2} \mathrm{O}_{2}$ ).

Bulk g- $\mathrm{C}_{3} \mathrm{~N}_{4}$ was prepared by direct pyrolysis of cyanamide. ${ }^{16}$ Polymeric bulk $\mathrm{g}-\mathrm{C}_{3} \mathrm{~N}_{4}$ is composed of $\mathrm{C}-\mathrm{N}$ layers, which stack in an $\mathrm{ABA}$ type fashion and are formed by weak van der Waals forces. After sonication in water, the bulk $\mathrm{g}-\mathrm{C}_{3} \mathrm{~N}_{4}$ was gradually exfoliated into ultrathin $\mathrm{g}-\mathrm{C}_{3} \mathrm{~N}_{4}$ nanosheets via the interaction of water molecules. ${ }^{17}$ The AFM image (Figure 1a) exhibits a thin layer structure of $\mathrm{g}-\mathrm{C}_{3} \mathrm{~N}_{4}$ nanosheets with a uniform thickness of $\sim 1.8 \mathrm{~nm}$, equal to five to six $\mathrm{CN}$ atomic monolayers. ${ }^{18}$ The structural features of $\mathrm{g}-\mathrm{C}_{3} \mathrm{~N}_{4}$ were verified by two signals in XRD pattern (Figure $\mathrm{S} 1$ in the SI) at $2 \theta$ of 27.6 and $13.0^{\circ}$, which originate from the $\langle 002\rangle$ interlayer diffraction of $\mathrm{C}-\mathrm{N}$ layers and inplanar repeated tri-s-triazine 

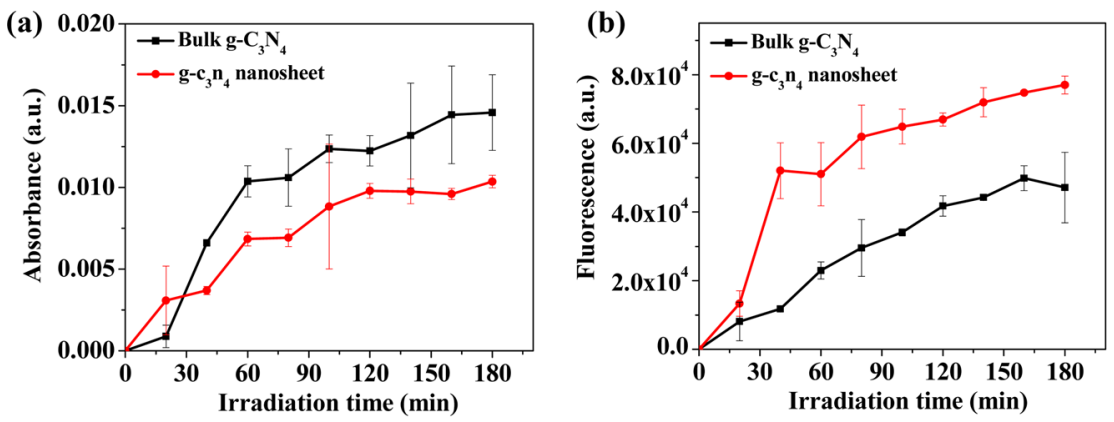

Figure 3. (a) $\cdot \mathrm{O}_{2}^{-}$, and (b) $\mathrm{H}_{2} \mathrm{O}_{2}$ generation curves over bulk $\mathrm{g}-\mathrm{C}_{3} \mathrm{~N}_{4}$ and $\mathrm{g}-\mathrm{C}_{3} \mathrm{~N}_{4}$ nanosheets under visible light irradiation.

units, respectively. ${ }^{11}$ The sharply reduced peaks after exfoliation indicate the few-layer structure of the $\mathrm{g}-\mathrm{C}_{3} \mathrm{~N}_{4}$ nanosheets. Indeed, because of the absence of any oxidation treatment, the crystal structure of bulk $\mathrm{g}-\mathrm{C}_{3} \mathrm{~N}_{4}$ was well-retained in the exfoliated nanosheets.

The electronic structures of the two types of $\mathrm{g}-\mathrm{C}_{3} \mathrm{~N}_{4}$ photocatalysts were investigated by a combined analysis of the optical absorption spectroscopy (Figure 1b) and MottSchottky plots (Figure 1c). Compared with bulk $\mathrm{g}-\mathrm{C}_{3} \mathrm{~N}_{4}$, the absorption edge of $\mathrm{g}^{-} \mathrm{C}_{3} \mathrm{~N}_{4}$ nanosheets displays a slight blue shift, accompanied by the bandgap broadening from 2.4 to 2.6 $\mathrm{eV}$. The Mott-Schottky plots reveal the typical n-type characteristics of $g-\mathrm{C}_{3} \mathrm{~N}_{4}$ due to the positive slope of the linear plots. ${ }^{19}$ The flat-band potentials derived from Mott-Schottky plots are about -1.30 and $-1.40 \mathrm{~V}$ (vs NHE) for the bulk and exfoliated $\mathrm{g}-\mathrm{C}_{3} \mathrm{~N}_{4}$, respectively. These results indicate the conduction and valence band edges of bulk g- $\mathrm{C}_{3} \mathrm{~N}_{4}$ shifted in opposite directions after exfoliation (Figure 1d), which are attributed to the quantum effect of a few-layer structure of g$\mathrm{C}_{3} \mathrm{~N}_{4}$ nanosheets.

Figure 2 displays the marked influence of $\mathrm{g}-\mathrm{C}_{3} \mathrm{~N}_{4}$ structure on their photocatalytic behavior during the phenol degradation. It was observed that phenol degradation over both $\mathrm{g}-\mathrm{C}_{3} \mathrm{~N}_{4}$ photocatalysts was fitted satisfactorily with a pseudo-first-order kinetic process (Figure S2 in the SI). The apparent rate constant for phenol photocatalytic degradation increased significantly from $0.18 \mathrm{~h}^{-1}$ on bulk g- $\mathrm{C}_{3} \mathrm{~N}_{4}$ to $0.57 \mathrm{~h}^{-1}$ on the exfoliated $\mathrm{g}_{-} \mathrm{C}_{3} \mathrm{~N}_{4}$ nanosheets. Control experiments in the absence of any catalysts or oxygen showed negligible phenol degradation, clearly indicating that $\mathrm{O}_{2}$ was required for phenol photocatalytic degradation. According to the classical photocatalytic theory, ${ }^{2,20} \mathrm{O}_{2}$ molecules can capture photogenerated electrons $\left(\mathrm{e}^{-}\right)$on $\mathrm{g}-\mathrm{C}_{3} \mathrm{~N}_{4}$, resulting in the great improvement of charge separation efficiency (eqs 1-4)

$$
\begin{aligned}
& \mathrm{O}_{2}+\mathrm{e}^{-} \rightarrow \cdot \mathrm{O}_{2}^{-} \\
& \mathrm{O}_{2}^{-}+\mathrm{H}^{+} \rightarrow \mathrm{HO}_{2} \cdot \\
& \mathrm{HO}_{2} \cdot+\mathrm{H}^{+}+\mathrm{e}^{-} \rightarrow \mathrm{H}_{2} \mathrm{O}_{2} \\
& \mathrm{O}_{2}+2 \mathrm{H}^{+}+2 \mathrm{e}^{-} \rightarrow \mathrm{H}_{2} \mathrm{O}_{2}
\end{aligned}
$$

Indeed, the important role of $\mathrm{O}_{2}$ during photocatalytic reaction over $\mathrm{g}-\mathrm{C}_{3} \mathrm{~N}_{4}$ was further verified by the enhanced phenol degradation in separate experiments with $\mathrm{O}_{2}$ bubbling (Figure $2 a, b)$.

Different ROS trapping experiments were then carried out on both bulk g- $\mathrm{C}_{3} \mathrm{~N}_{4}$ and $\mathrm{g}-\mathrm{C}_{3} \mathrm{~N}_{4}$ nanosheets to investigate the photocatalytic mechanism of $\mathrm{g}-\mathrm{C}_{3} \mathrm{~N}_{4}$. As shown in Figure $2 \mathrm{c}, \mathrm{d}$, hole scavenger TEOA significantly inhibited phenol degrada- tion, implying that photogenerated holes are critically important for phenol degradation on both $\mathrm{g}-\mathrm{C}_{3} \mathrm{~N}_{4}$ catalysts. On the contrary, the phenol degradation efficiency was reduced by $<2$ and $15 \%$ with the addition of $\cdot \mathrm{OH}$ scavenger tert-butyl alcohol over bulk g- $\mathrm{C}_{3} \mathrm{~N}_{4}$ and $\mathrm{g}-\mathrm{C}_{3} \mathrm{~N}_{4}$ nanosheets, respectively, revealing that $\cdot \mathrm{OH}$ radicals play a minor role in phenol degradation. Indeed, according to Figure $1 \mathrm{~d}$, because the valence band potential of both $\mathrm{g}-\mathrm{C}_{3} \mathrm{~N}_{4}$ catalysts is more negative than that of $\mathrm{OH} / \mathrm{OH}^{-}(+1.99 \mathrm{~V}$, vs NHE $){ }^{21}$ the photogenerated holes are incapable of oxidizing adsorbed $\mathrm{OH}^{-}$ groups into $\cdot \mathrm{OH}$ radicals. This suggests $\cdot \mathrm{OH}$ radicals generated in both $\mathrm{g}-\mathrm{C}_{3} \mathrm{~N}_{4}$ catalysts may result from molecular $\mathrm{O}_{2}$ reduction by photogenerated electrons. Because $\mathrm{H}_{2} \mathrm{O}_{2}$ is an important product of $\mathrm{O}_{2}$ reduction by photogenerated electrons (eqs 1-4), the effect of $\mathrm{H}_{2} \mathrm{O}_{2}$ scavenger catalase on the phenol degradation was also investigated. It was found that the phenol degradation efficiency in the presence of $\mathrm{H}_{2} \mathrm{O}_{2}$ scavenger was almost equal to that of $\cdot \mathrm{OH}$ radical scavenger, implying that $\cdot \mathrm{OH}$ was mainly from the decomposition $\mathrm{H}_{2} \mathrm{O}_{2}$. It is worth noting that although $\cdot \mathrm{OH}$ radicals generated by molecular $\mathrm{O}_{2}$ reduction contributed only slightly to the degradation efficiency, molecular $\mathrm{O}_{2}$ activation process on g$\mathrm{C}_{3} \mathrm{~N}_{4}$ surface still significantly influences the following photocatalytic phenol degradation reaction (Figure 2a,b).

The selectively increased contribution of $\mathrm{H}_{2} \mathrm{O}_{2}$ and $\cdot \mathrm{OH}$ on phenol degradation over $\mathrm{g}-\mathrm{C}_{3} \mathrm{~N}_{4}$ nanosheet implied distinct different molecular $\mathrm{O}_{2}$ activation processes on bulk g- $\mathrm{C}_{3} \mathrm{~N}_{4}$ and g- $\mathrm{C}_{3} \mathrm{~N}_{4}$ nanosheets surfaces. As illustrated in eqs $1-4$, there are two possible pathways for oxygen reduction by photoexcited electrons: one is a sequential one-electron reduction process to . $\mathrm{O}_{2}{ }^{-}$and $\mathrm{H}_{2} \mathrm{O}_{2}$ and the other is a two-electron process to $\mathrm{H}_{2} \mathrm{O}_{2}$. To check out the molecular $\mathrm{O}_{2}$ activation pathways on g$\mathrm{C}_{3} \mathrm{~N}_{4}$ surfaces, the amount of $\cdot \mathrm{O}_{2}^{-}$and $\mathrm{H}_{2} \mathrm{O}_{2}$ produced on $\mathrm{g}$ $\mathrm{C}_{3} \mathrm{~N}_{4}$ bulk material and nanosheet under illumination was quantified by using an ROS-selective fluorescent or colorimetric probe (Figure 3). According to the aforementioned discussion, the possibility of $\mathrm{H}_{2} \mathrm{O}_{2}$ generated via photogenerated holes of g- $\mathrm{C}_{3} \mathrm{~N}_{4}$ oxidation is ruled out due to the lack of $\cdot \mathrm{OH}$ originating from the hole. If the generation pathways of $\mathrm{H}_{2} \mathrm{O}_{2}$ are the same via a sequential single-electron reduction of $\mathrm{O}_{2}$ on both $\mathrm{g}-\mathrm{C}_{3} \mathrm{~N}_{4}$ photocatalysts, more $\mathrm{H}_{2} \mathrm{O}_{2}$ should be generated from bulk g$\mathrm{C}_{3} \mathrm{~N}_{4}$ because more $\cdot \mathrm{O}_{2}^{-}$was detected. Unexpectedly, an interesting observation came from the markedly depressed $\cdot \mathrm{O}_{2}{ }^{-}$ generation and greatly enhanced $\mathrm{H}_{2} \mathrm{O}_{2}$ production after the exfoliation (Figure 3 and Figure $\mathrm{S} 3$ in the $\mathrm{SI}$ ). This result further implies a significant change of $\mathrm{O}_{2}$ reduction process on the $\mathrm{g}-\mathrm{C}_{3} \mathrm{~N}_{4}$ surface after exfoliation. It can be temporarily assumed that $\mathrm{H}_{2} \mathrm{O}_{2}$ is generated by a sequential single-electron reduction pathway $\left(\mathrm{O}_{2} \rightarrow \cdot \mathrm{O}_{2}^{-} \rightarrow \mathrm{H}_{2} \mathrm{O}_{2}\right)$ on bulk g- $\mathrm{C}_{3} \mathrm{~N}_{4}$ 
surface, while one two-electron reduction of $\mathrm{O}_{2}$ to form $\mathrm{H}_{2} \mathrm{O}_{2}$ would occur on $\mathrm{g}-\mathrm{C}_{3} \mathrm{~N}_{4}$ nanosheets surface. The generated $\mathrm{H}_{2} \mathrm{O}_{2}$ could be converted into $\cdot \mathrm{OH}$ radicals by either photogenerated electrons or visible-light irradiation and subsequently participate in the photocatalytic reaction. ${ }^{22}$ As shown in Figure S4 in the SI, more $\cdot \mathrm{OH}$ was detected over g$\mathrm{C}_{3} \mathrm{~N}_{4}$ nanosheets because more $\mathrm{H}_{2} \mathrm{O}_{2}$ was produced, which accelerated the phenol photodegradation over $\mathrm{g}-\mathrm{C}_{3} \mathrm{~N}_{4}$ nanosheets. This result is consistent with the photocatalytic trapping experiments.

The selective pathway for molecular $\mathrm{O}_{2}$ reduction on the two photoexcited g- $\mathrm{C}_{3} \mathrm{~N}_{4}$ catalysts was further validated by Raman spectroscopic measurements. As shown in Figure 4a, fresh

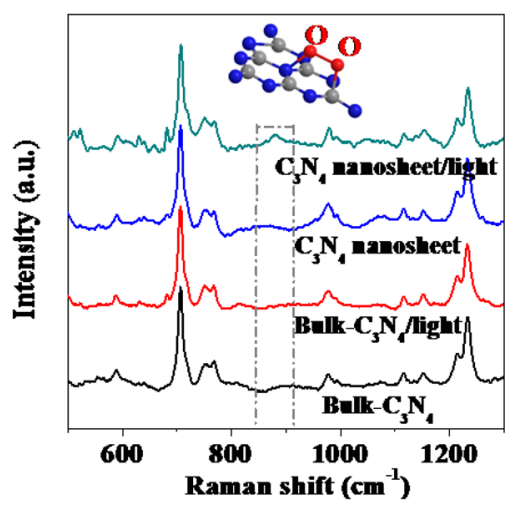

Figure 4. Raman spectra of $\mathrm{g}-\mathrm{C}_{3} \mathrm{~N}_{4}$ samples before and after $5 \mathrm{~h}$ of visible-light illumination in an $\mathrm{O}_{2}$ bubbling suspension. Inset shows the structure of 1,4-endoperoxide (intermediate of two-electron $\mathrm{O}_{2}$ reduction).

samples of the two photocatalysts exhibited similar Raman bands, the ones at 706 and $977 \mathrm{~cm}^{-1}$ corresponding to the breathing modes of triazine rings and the one at $750 \mathrm{~cm}^{-1}$ for the out-of-plane bending mode of the graphitic domains. ${ }^{23}$ After irradiation in $\mathrm{O}_{2}$ bubbling suspension, a new broad band at $882 \mathrm{~cm}^{-1}$ was observed on $\mathrm{g}-\mathrm{C}_{3} \mathrm{~N}_{4}$ nanosheets, which is assigned to 1,4 -endoperoxide. ${ }^{24}$ It is noted that the concentration of 1,4-endoperoxide in the suspension is low due to the subsequent conversion of this species to $\mathrm{H}_{2} \mathrm{O}_{2}$. A long irradiation time is needed to accumulate enough 1,4endoperoxide for Raman spectroscopic measurements. Photoexcited generation of 1,4-endoperoxide species provides strong evidence of the occurrence of two-electron reduction of $\mathrm{O}_{2}$ on g- $\mathrm{C}_{3} \mathrm{~N}_{4}$ nanosheet surface. In contrast, no such Raman band was detected on the bulk $\mathrm{g}-\mathrm{C}_{3} \mathrm{~N}_{4}$. In a previous study, 1,4endoperoxide was detected by Raman spectroscopy on photoactivated bulk $\mathrm{g}-\mathrm{C}_{3} \mathrm{~N}_{4}$ in the presence of ethanol. ${ }^{24}$ Presumably, the sacrificial electron donor quenched photogenerated holes and increased the yield of 1,4-endoperoxide. In the present work, 1,4-endoperoxide production was enhanced by exfoliating the photocatalyst without the use of any electron donor. This result confirms the switch of molecular oxygen activation from one-electron transfer to two-electron transfer by exfoliating bulk g- $\mathrm{C}_{3} \mathrm{~N}_{4}$.

On the basis of the above results, a proposed mechanism of selective $\mathrm{O}_{2}$ activation process on photoexcited g- $\mathrm{C}_{3} \mathrm{~N}_{4}$ samples is depicted in Scheme 1. On bulk $\mathrm{g}-\mathrm{C}_{3} \mathrm{~N}_{4}$, as reported by Shiraishi et al., without any additional agent or modifiers, ${ }^{24,25}$ one electron generated from $\mathrm{g}-\mathrm{C}_{3} \mathrm{~N}_{4}$ photoexcitation reduces $\mathrm{O}_{2}$ and produces surface-associated superoxo species, which then gets protonated and dissociates from the surface and converted into $\mathrm{HO}_{2}$. radical. In contrast, on $\mathrm{g}-\mathrm{C}_{3} \mathrm{~N}_{4}$ nanosheets, some superoxo species are reduced very rapidly by another photoelectron to produce a surface-stabilized intermediate, which subsequently convert into $\mathrm{H}_{2} \mathrm{O}_{2}{ }^{25}$ The rapid formation of 1,4-endoperoxide removes two electrons almost simultaneously from $\mathrm{g}-\mathrm{C}_{3} \mathrm{~N}_{4}$ nanosheets and thus stabilizes more holes available for phenol oxidation. On the bulk $\mathrm{g}-\mathrm{C}_{3} \mathrm{~N}_{4}$, oneelectron reduction process leads to less electron-hole separation and low $\mathrm{H}_{2} \mathrm{O}_{2}$ formation efficiency and subsequently reduces phenol degradation rate. The origin of preferred twoelectron reduction of oxygen on $\mathrm{g}-\mathrm{C}_{3} \mathrm{~N}_{4}$ nanosheets is not clear yet, but we hypothesize that the surface energy of $\mathrm{g}-\mathrm{C}_{3} \mathrm{~N}_{4}$ increases after exfoliation, which indicates that $\mathrm{g}-\mathrm{C}_{3} \mathrm{~N}_{4}$ nanosheets may prefer to recombine with oxygen molecule to stabilize their states and thus facilities the formation of 1,4endoperoxide. It is noted that although one-electron reduction is a much more common process due to the slow kinetics of two-electron reduction, however, the rapid formation of 1,4endoperoxide on $\mathrm{g}-\mathrm{C}_{3} \mathrm{~N}_{4}$ nanosheets may accelerate the rate of two-electron transfer process and thus give rise to switch the oxygen activation from one-electron reduction to two-electron reduction process by exfoliating bulk g- $\mathrm{C}_{3} \mathrm{~N}_{4}$. In addition, the $2 \mathrm{D}$ nanosheet structure with a thickness of $<2 \mathrm{~nm}$ provides a much shorter distance than the bulk material for the photogenerated electrons to travel to the catalyst surface and then reduce superoxo before it is released from the surface. This process was further examined by the electrochemical reduction of $\mathrm{O}_{2}$ on $\mathrm{g}-\mathrm{C}_{3} \mathrm{~N}_{4}$ film electrodes (Figure $\mathrm{S} 5$ in the $\mathrm{SI})$. On both types of $\mathrm{g}-\mathrm{C}_{3} \mathrm{~N}_{4}$ electrodes negligible current was

Scheme 1. Proposed Two Oxygen Reduction Pathways on Photoexcited Bulk g- $\mathrm{C}_{3} \mathrm{~N}_{4}$ and g- $\mathrm{C}_{3} \mathrm{~N}_{4}$ Nanosheet Surfaces

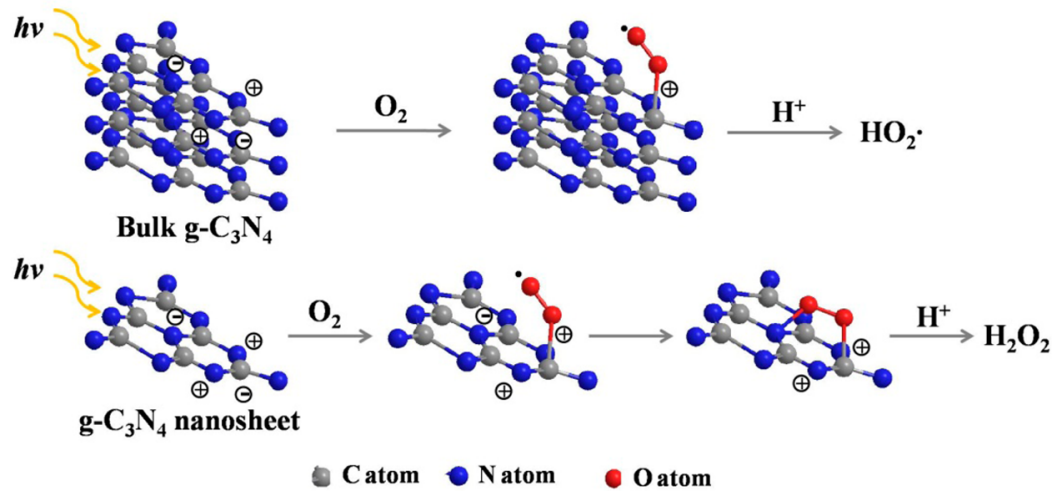


observed in the absence of $\mathrm{O}_{2}$. In an $\mathrm{O}_{2}$-saturated solution, reduction current with an onset voltage of $\sim 80 \mathrm{mV}$ (vs NHE) was observed on the bulk g- $\mathrm{C}_{3} \mathrm{~N}_{4}$ electrode, indicating that $\mathrm{O}_{2}$ reduction reaction occurred on this surface. Importantly, larger $\mathrm{O}_{2}$ reduction current was observed on the $\mathrm{g}-\mathrm{C}_{3} \mathrm{~N}_{4}$ nanosheet electrode and the onset potential shifted positively by $\sim 40 \mathrm{mV}$, suggesting the exfoliated $\mathrm{g}-\mathrm{C}_{3} \mathrm{~N}_{4}$ nanosheet greatly promoted $\mathrm{O}_{2}$ reduction. This is consistent with the enhanced ROS generation on $\mathrm{g}_{-} \mathrm{C}_{3} \mathrm{~N}_{4}$ nanosheet due to the efficient twoelectron transfer process, which contributes to their enhanced photocatalytic activity.

A cycling photocatalytic degradation experiment proceeded with $15 \mathrm{~h}$ of visible light irradiation to evaluate the stability and reusability of the $\mathrm{g}-\mathrm{C}_{3} \mathrm{~N}_{4}$ nanosheet photocatalyst. As shown in Figure S6 in the SI, the high photocatalytic activity of $\mathrm{g}-\mathrm{C}_{3} \mathrm{~N}_{4}$ nanosheet was well maintained during the five repeated cycles. The result demonstrated excellent stability of $\mathrm{g}-\mathrm{C}_{3} \mathrm{~N}_{4}$ nanosheet for photocatalytic degradation. The high photocatalytic activity and good stability of g- $\mathrm{C}_{3} \mathrm{~N}_{4}$ nanosheet endow it great potential for practical applications.

In summary, selective reduction of molecular oxygen on bulk g- $\mathrm{C}_{3} \mathrm{~N}_{4}$ and $\mathrm{g}-\mathrm{C}_{3} \mathrm{~N}_{4}$ nanosheet was demonstrated. The bulk g$\mathrm{C}_{3} \mathrm{~N}_{4}$ prefers to reduce $\mathrm{O}_{2}$ to $\cdot \mathrm{O}_{2}^{-}$via one-electron reduction, while the photoexcited $\mathrm{g}-\mathrm{C}_{3} \mathrm{~N}_{4}$ nanosheet promotes the twoelectron reduction of $\mathrm{O}_{2}$ to yield $\mathrm{H}_{2} \mathrm{O}_{2}$ due to the efficient formation of 1,4-endoperoxide species. The efficient twoelectron reduction of $\mathrm{O}_{2}$ on the $\mathrm{g}^{-} \mathrm{C}_{3} \mathrm{~N}_{4}$ nanosheet surface promotes hole generation and subsequently accelerates phenol oxidation degradation. These findings provide some new insights into the molecular $\mathrm{O}_{2}$ reactions on semiconductor surface during photocatalytic reactions, which could help us to design efficient photocatalysts for environmental applications.

\section{ASSOCIATED CONTENT}

\section{S Supporting Information}

Experimental methods, XRD patterns, photodegradation kinetics of phenol over bulk g- $\mathrm{C}_{3} \mathrm{~N}_{4}$ and $\mathrm{g}_{-} \mathrm{C}_{3} \mathrm{~N}_{4}$ nanosheet under visible light, $\cdot \mathrm{OH}$ generation curves on both $\mathrm{g}-\mathrm{C}_{3} \mathrm{~N}_{4}$ samples, current-potential curves of the $\mathrm{g}-\mathrm{C}_{3} \mathrm{~N}_{4}$ electrodes, and cycling runs of $\mathrm{g}-\mathrm{C}_{3} \mathrm{~N}_{4}$ nanosheet for photodegradation of phenol. This material is available free of charge via the Internet at http://pubs.acs.org.

\section{AUTHOR INFORMATION}

\section{Corresponding Author}

*Phone: 86 10-62849685. E-mail: LHGuo@rcees.ac.cn.

\section{Notes}

The authors declare no competing financial interest.

\section{ACKNOWLEDGMENTS}

This work was supported by the National Basic Research Program of China (2011CB936001) and National Nature Science Foundation of China (21321004, 21207146, 21177138, 21377142, and 21477146).

\section{REFERENCES}

(1) Hoffmann, M. R.; Martin, S. T.; Choi, W.; Bahnemann, D. W. Environmental Applications of Semiconductor Photocatalysis. Chem. Rev. 1995, 95, 69-96.

(2) Teoh, W. Y.; Scott, J. A.; Amal, S. Progress in Heterogeneous Photocatalysis: From Classical Radical Chemistry to Engineering Nanomaterials and Solar Reactors. J. Phys. Chem. Lett. 2012, 3, 629639.
(3) Xu, W.; Jain, P. K.; Beberwyck, B. J.; Alivisatos, A. P. Probing Redox Photocatalysis of Trapped Electrons and Holes on Single Sbdoped Titania Nanorod Surfaces. J. Am. Chem. Soc. 2012, 134, 39463949.

(4) Ishibashi, K.; Nosaka, Y.; Hashimoto, K.; Fujishima, A. TimeDependent Behavior of Active Oxygen Species Formed on Photoirradiated $\mathrm{TiO}_{2}$ Films in Air. J. Phys. Chem. B 1998, 102, 2117-2120.

(5) Zhang, J.; Nosaka, Y. Mechanism of the $\mathrm{OH}$ Radical Generation in Photocatalysis with $\mathrm{TiO}_{2}$ of Different Crystalline Types. J. Phys. Chem. C 2014, 118, 10824-10832.

(6) Zhang, M.; Wang, Q.; Chen, C. C.; Zhang, L.; Ma, W. H.; Zhao, J. C. Oxygen Atom Transfer in the Photocatalytic Oxidation of Alcohols by $\mathrm{TiO}_{2}$ : Oxygen Isotope Studies. Angew. Chem., Int. Ed. 2009, 48, 6081-6084.

(7) Teranishi, M.; Naya, S.; Tada, H. In Situ Liquid Phase Synthesis of Hydrogen Peroxide from Molecular Oxygen Using Gold Nanoparticle-Loaded Titanium(IV) Dioxide Photocatalyst. J. Am. Chem. Soc. 2010, 132, 7850-7851.

(8) Nosaka, Y.; Takahashi, S.; Sakamoto, H.; Nosaka, A. Reaction Mechanism of $\mathrm{Cu}$ (II)-Grafted Visible-Light Responsive $\mathrm{TiO}_{2}$ and $\mathrm{WO}_{3}$ Photocatalysts Studied by Means of ESR Spectroscopy and Chemiluminescence Photometry. J. Phys. Chem. C 2011, 115, 2128321290.

(9) Zhao, Y.; Ma, W.; Li, Y.; Ji, H.; Chen, C.; Zhu, H.; Zhao, J. The Surface-Structure Sensitivity of Dioxygen Activation in the AnatasePhotocatalyzed Oxidation Reaction. Angew. Chem., Int. Ed. 2012, 51, 3188-3192.

(10) Zhao, K.; Zhang, L.; Wang, J.; Li, Q.; He, W.; Yin, J. J. Surface Structure-Dependent Molecular Oxygen Activation of BiOCl SingleCrystalline Nanosheets. J. Am. Chem. Soc. 2013, 135, 15750-15753.

(11) Wang, X.; Maeda, K.; Thomas, A.; Takanabe, K.; Xin, G.; Carlsson, J. M.; Domen, K.; Antonietti, M. A Metal-Free Polymeric Photocatalyst for Hydrogen Production from Water under Visible Light. Nat. Mater. 2009, 8, 76-80.

(12) Ida, S.; Ishihara, T. Recent Progress in Two-Dimensional Oxide Photocatalysts for Water Splitting. J. Phys. Chem. Lett. 2014, 5, 25332542.

(13) Cao, S.; Yu, J. g- $\mathrm{C}_{3} \mathrm{~N}_{4}$-Based Photocatalysts for Hydrogen Generation. J. Phys. Chem. Lett. 2014, 5, 2101-2107.

(14) Xu, J.; Zhang, L.; Shi, R.; Zhu, Y. Chemical Exfoliation of Graphitic Carbon Nitride for Efficient Heterogeneous Photocatalysis. J. Mater. Chem. A 2013, 1, 14766-14772.

(15) Wang, H.; Su, Y.; Zhao, H.; Yu, H.; Chen, S.; Zhang, Y.; Quan, $\mathrm{X}$. Photocatalytic Oxidation of Aqueous Ammonia Using Atomic Single Layer Graphitic- $\mathrm{C}_{3} \mathrm{~N}_{4}$. Environ. Sci. Technol. 2014, 48, 1198411990.

(16) Li, X.-H.; Zhang, J.; Chen, X.; Fischer, A.; Thomas, A.; Antonietti, M.; Wang, X. Condensed Graphitic Carbon Nitride Nanorods by Nanoconfinement: Promotion of Crystallinity on Photocatalytic Conversion. Chem. Mater. 2011, 23, 4344-4348.

(17) Zhang, X.; Xie, X.; Wang, H.; Zhang, J.; Pan, B.; Xie, Y. Enhanced Photoresponsive Ultrathin Graphitic-Phase $\mathrm{C}_{3} \mathrm{~N}_{4}$ Nanosheets for Bioimaging. J. Am. Chem. Soc. 2013, 135, 18-21.

(18) Groenewolt, M.; Antonietti, M. Synthesis of $\mathrm{g}-\mathrm{C}_{3} \mathrm{~N}_{4}$ Nanoparticles in Mesoporous Silica Host Matrices. Adv. Mater. 2005, 17, $1789-1792$.

(19) Zhang, J.; Chen, X.; Takanabe, K.; Maeda, K.; Domen, K.; Epping, J. D.; Fu, X.; Antonietti, M.; Wang, X. Synthesis of a Carbon Nitride Structure for Visible-Light Catalysis by Copolymerization. Angew. Chem., Int. Ed. 2010, 49, 441-444.

(20) Turchi, C. S.; Ollis, D. F. Photocatalytic Degradation of Organic Water Contaminants: Mechanisms Involving Hydroxyl Radical Attack. J. Catal. 1990, 122, 178-192.

(21) Kim, S.; Choi, W. Kinetics and Mechanisms of Photocatalytic Degradation of $\left(\mathrm{CH}_{3}\right)_{n} \mathrm{NH}_{4-n}{ }^{+}(0 \leq n \leq 4)$ in $\mathrm{TiO}_{2}$ Suspension: The Role of OH Radicals. Environ. Sci. Technol. 2002, 36, 2019-2025.

(22) Li, W. J.; Li, D. Z.; Lin, Y. M.; Wang, P. X.; Chen, W.; Fu, X. Z.; Shao, Y. Evidence for the Active Species Involved in the Photo- 
degradation Process of Methyl Orange on $\mathrm{TiO}_{2}$. J. Phys. Chem. C 2012, 116, 3552-3560.

(23) Zinin, P. V.; Ming, L. C.; Sharma, S. K.; Khabashesku, V. N.; Liu, X.; Hong, S.; Endo, S.; Acosta, T. Ultraviolet and Near-Infrared Raman Spectroscopy of Graphitic $\mathrm{C}_{3} \mathrm{~N}_{4}$ Phase. Chem. Phys. Lett. 2009, 472, 69-73.

(24) Shiraishi, Y.; Kanazawa, S.; Sugano, Y.; Tsukamoto, D.; Sakamoto, H.; Ichikawa, S.; Hirai, T. Highly Selective Production of Hydrogen Peroxide on Graphitic Carbon Nitride $\left(\mathrm{g}-\mathrm{C}_{3} \mathrm{~N}_{4}\right)$ Photocatalyst Activated by Visible Light. ACS Catal. 2014, 4, 774-780.

(25) Shiraishi, Y.; Kanazawa, S.; Kofuji, Y.; Sakamoto, H.; Ichikawa, S.; Tanaka, S.; Hirai, T. Sunlight-Driven Hydrogen Peroxide Production from Water and Molecular Oxygen by Metal-Free Photocatalysts. Angew. Chem., Int. Ed. 2014, 53, 13454-13459. 